\title{
You Complete Me: Posthumous Works and Secondary Agency
}

\author{
Sondra Bacharach, Victoria University of Wellington \\ Deborah Tollefsen, Memphis University
}

(This is a pre-print. Please cite the final version, published at Journal of Aesthetic

Education:

https://www.muse.jhu.edu/article/597710

Many works are attributed to artists after their death, even when someone else has contributed substantively to the content of the work or when the work left by the artist is deemed incomplete by any standard of completion. Call these works posthumous works. These cases give rise to several interesting and related questions about the ontology of artworks and authorship: If the works are incomplete when the first artist dies, then can someone else complete them, or do they remain forever unfinished? Are works that are altered after the artist's death new and distinct works? If they remain forever unfinished, then what is the unfinished works' relation to the putatively "finished" work? If, on the other hand, they can be finished and are finished by someone other than the original artist (since the original artist is dead), then to whom to do we give credit: the deceased artist, the finishing artist, or both? Recent accounts of when an artwork is complete make posthumous works impossible. In this paper, we offer an explanation of how the unfinished work of the dead can be completed and why in these cases attributing the work to the dead is justified.

Many works are attributed to artists after their death, even when someone else has contributed substantively to the content of the work or when the work left by the artist is deemed incomplete by any standard of completion. Call these works, posthumous works. Consider, for instance, Garden of Eden (commonly attributed to Hemingway), Mysterious Stranger (commonly attributed to Mark Twain), Silmarillion (commonly attributed to Tolkien), Symphony No. 10 (commonly attributed to Beethoven), Symphony No. 7 (commonly attributed to Schubert), Sagrada Familia (commonly attributed to Gaudí), the film A.I. (commonly attributed to Kubrick), Woyzeck (commonly attributed to Büchner), to name just a few. These are examples where one artist starts a work, dies before it is complete (by any standard of completeness), and another artist putatively "finishes" the work that was begun by the original artist. These cases give rise to several interesting and related questions about the ontology of artworks and authorship: If the works are incomplete when the first artist dies, then can someone else complete them posthumously or do they remain forever unfinished? Are works that are altered after the artist's death new and distinct works? If they remain forever unfinished, then what is the unfinished works' relation to the putatively "finished" work? If, on the other hand, they can be finished, and they are finished by someone other than the original 
artist (since the original artist is dead) then to whom to do we give credit: the deceased artist, the finishing artist, or both?

Recent trends in art scholarship acknowledge the central role that collaborators have played in the art-making process, roles that art scholars have been able to ignore in the past. In the spirit of giving credit where credit is due, art historians increasingly strive to recognize the impact of even so-called "minor" artists who may have worked in someone's workshop or studio; in a similar vein, literary scholars make lengthy studies of unseen and often overlooked editorial contributions that frequently change a literary works' essential character, plot or tone. The field of research and scholarship in the arts is changing: with more and more studies investigating these collaborations, and with the growing acceptance of the degree to which art-making is social and collaborative, researchers in the arts need to expand their methodology to include tools that can assess the nature and role of artistic collaborations. Philosophers have responded quickly, as the recent explosion of philosophical literature on collaboration in the arts highlights.

The situation is not so clear-cut, however, in cases of posthumous works. In a traditional collaboration, two (or more) people work together to complete a work, coordinating their actions and their minds. But, of course, in posthumously completed works, there is no real sense of collaboration to be had. So, a special conundrum arises for posthumous works: on the one hand, multiple artists contribute to a particular work; but, on the other, they do not seem to do so collaboratively in any meaningful sense. Current accounts of collaboration will not work so well in solving the puzzle of posthumous authorship. This essay hopes to contribute to aesthetic education by exploring the way in which artworks can be completed posthumously and how this impacts our aesthetic understanding of such works, in particular, our attributions of authorship in cases of posthumously completed works.

How one answers questions about posthumous works will depend, in part, on how one answers prior ontological questions regarding the conditions under which a work is finished. In this paper we consider two leading theories of when a work of art is complete (that of Darren Hick and Paisley Livingston) and show how each has counterintuitive results for the case of posthumous works. In order to handle the case of posthumous works we need to reconsider (1) the conditions under which a work of art is finished, (2) the conditions under which a work of art is no longer the same work of art but a new and distinct work, and (3) the types of agency involved in authorship.

\section{Unfinished Works}

The questions raised by posthumous authorship stem from more general questions regarding when a work is complete. Paisley Livingston has written extensively on this difficult issue. ${ }^{1}$ He makes a useful distinction between genetic completion and aesthetic completion: A work is aesthetically complete when it exhibits certain essential characteristics of the relevant artistic category. But sometimes a work is complete even when it does not exhibit all the relevant characteristics of a certain category. Livingston offers the example of baroque fragments, works that are designed to look aesthetically incomplete but are nonetheless complete. Livingston calls this other sense of completeness "genetic completeness." According to Livingston, in order for a work to be genetically complete, the artist must decide that the work is complete: 
Roughly put, a work is genetically complete only if its maker or makers decide it is so. ${ }^{2}$

The completion decision involves more than simply a decision to stop working. The artist not only makes a retrospective decision to cease working but also makes a prospective decision that she will not take up the work again in the future.

To sum up, my idea is that in a range of relatively simple cases, the decision to stop working is not enough to constitute a completed work unless it is accompanied by a retrospective judgment that this work and its creation are thereby complete, at least as far as the artist's own contributions are concerned. This sort of complex genetic attitude is, I suggest, a necessary but not a sufficient condition of the making of a work of art in a range of standard cases. ${ }^{3}$

Livingston has subsequently refined his analysis, to include an extended completion decision. ${ }^{4}$ The extended completion decision is meant to capture cases where the artist agrees to relinquish control over when the work is finished to some predetermined procedure. In these cases the work is finished when that predetermined procedure has been implemented:

I had in mind speed painting competitions where it is agreed in advance that a work will be finished when a certain time limit has expired (unless the artist chooses to stop before that limit has been reached). Perhaps it would be good enough to say that in all cases where the artist agrees in advance to some "stopping rule" or decision procedure that will not have to depend upon his or her own subsequent decision about the work's completion, that other procedure is what is necessary to work completion. We can call this disjunction of two types of cases the artist's "extended completion decision," and although universal claims about this messy terrain are risky, this sort of decision may be provisionally advanced as a necessary condition on all work completion. ${ }^{5}$

Moved by Hick's considerations regarding the role of publication in determining when a work of art is finished, Livingston supplements the extended completion decision in the following manner:

...a work is finished just in case the artist, working in the absence of severe coercion, makes the extended completion decision, and either (1) the artist consents to make the work available to a public and the work is actually published (where the public is not solely comprised of the artist and his or her friends and family), or (2) the artist does not consent to publication, but does not subsequently override the completion decision and make or authorize additional changes incompatible with that prior decision. ${ }^{6}$

More recently, Livingston has refined this definition in his "Artistic Collaboration and the completion of Works of Art", adding the idea that a completion decision can be effective, as well as extended:

a work of art is finished if and only if the artist, working in the absence of severe coercion, makes an effective completion decision of the simple or extended form (as discussed above). A decision is effective, we have proposed, whenever the artist does 
not subsequently override the decision and make or authorize artistic changes incompatible with that prior decision.

For convenience, we can use the expression 'effective completion decision' to cover ordinary cases in which the artist decides that something is a finished work and refrains from making further changes, as well as cases where the artist makes what we have called an 'extended' completion decision, that is, one in which the artist settles on a procedure that requires some form of external process to occur if the work is to be finished. ${ }^{7}$

Livingston does not explicitly consider the case of unfinished work that is taken up by someone else. But, it would seem that, if an author dies before having made an effective completion decision, the work remains not only unfinished but permanently unfinished, given that the effective completion decision is a necessary condition for a work of art to be complete. When there is no effective completion decision, the work is a mere fragment.

That the artist's decision is a key element in a work's completion is easily illustrated by reference to the many cases where an artist's activity is interrupted and terminated involuntarily. Death, illness, and various external events and circumstances can put a stop to the creative process, leaving the work unfinished, and we deem it relevant to distinguish all such cases from those where it is the artist's judgment that settles the matter. ${ }^{8}$

Livingston does suggest that in some restricted set of cases when the author dies without making an effective completion decision, we can hypothesize that they would have deemed it complete and so the work has a sort of quasi-complete status:

Perhaps the artist would have reached such a decision, but was prevented from doing so as a result of circumstance, but in such a case we are still left with something that is distinct from the classically complete work of art. We can say, however, that had the artist had time to reach a conclusion, he or she would have deemed the item complete, and so the artefact enjoys a kind of conditional completion. ${ }^{9}$

These are perhaps cases in which the work is all but complete and minor editing is required. It is unclear from what Livingston says whether he thinks that such works, if they were to be edited and published, would constitute complete works or whether their status would always remain conditional. It seems clear, however, that in cases where there were more substantive changes made by literary executors or editors after the death of the artist, the work would remain forever incomplete, since the artist is unable to make a completion decision regarding those changes (since they take place after her death).

Darren Hick has criticized Livingston's theory of completion by raising a number of counterexamples designed to challenge the idea that a completion decision is necessary for a work to be complete. Rather than offer a necessary condition, Hick identifies a sufficient condition for completeness:

SC4a: Provided no explicit declaration by the artist to the contrary, publication of a work with the artist's uncoerced consent is a sufficient condition of that work's 
being finished. ${ }^{10}$

Publication, for Hick, is a broad notion and the standards for what counts as published differ across media. Roughly, Hick has in mind the notion of making the work accessible to the public or releasing the work for public consumption.

Like Livingston's account, Hick's account of completion has difficulty

accommodating posthumous works. Although Hick claims to give only a sufficient condition for a work to be finished, he seems to treat it as a necessary condition in the case of death. When an artist dies and the artist did not offer her consent to publish the work (because her death was untimely or for some other reason), the work remains, according to Hick, incomplete at the time of death and remains forever incomplete. In this respect, he and Livingston seem to agree that completing a work after the death of the author is impossible. Moreover, Hick specifies that if someone alters an incomplete work left by the deceased artist and then publishes it (or merely publishes work that the author did not explicitly consent to have published), this results in a new and different work:

Regarding works left unfinished at the artists' respective death, I suspect we want to say that they will never be finished. Indeed, this would seem to be the case...Rather, they [the posthumously completed works] must be regarded as different works, and this, I suspect, is not an objectionable result. ${ }^{11}$

Hick, unlike Livingston, is committed to there being two metaphysically distinct entities in all cases of so-called posthumously completed works: (1) the fragment or unfinished work that exists at the time of the author's death and (2) a new work which is metaphysically distinct from the unfinished work or fragment and which is brought about by some intervention by another author or authors.

Despite Hick's more robust ontological claims, Hick and Livingston both agree about the status of the unfinished work of the dead. When an author dies without either consenting to publication or making an effective completion decision, the works remain forever unfinished. There is no sense to be made of finishing an unfinished work. Completing the work of the dead is impossible.

\section{Is Posthumous Completion Really Impossible?}

Although there are cases where an unfinished work has been so dramatically altered after the death of the author that we deem it distinct from the work that was left behind, not all posthumous works are like this. For instance, imagine a case where a novel is unfinished at the time of the author's death (perhaps the author died unexpectedly) but there are only small changes that need to be done in order to render the story consistent. If the author died unexpectedly, then he would have neither explicitly consented to publication nor made an effective completion decision as characterized by Livingston. Indeed, perhaps the author had plans to pick up the work the next day and make those final changes himself. Are we really to say that the editor is unable to finish the artist's work? And do we really want to say, as Hick does, that when the editor makes these small changes, the editor thereby creates a new work, different and distinct from the now-deceased artist's work? We don't think so. 
Perhaps Livingston will deem these cases conditionally complete. After all, they involve very minor changes and we can suppose that the author would have made a completion decision, had he not died unexpectedly. Perhaps conditionally complete works are simply those where, if the author were to have had more time to complete it, he would have deemed it complete. But this is problematic, because this counterfactual is true of a great many works of art and hence doesn't discriminate between works that are conditionally complete and those that will remain forever incomplete. Further, it seems unlikely that the editor (or whoever is making the changes) sees himself as working on a forever conditionally complete text. Rather, the editor is attempting to finish an unfinished work and, when successful, to render that work unconditionally complete. Livingston doesn't tell us the conditions under which a conditionally complete text can be completed. But perhaps he would allow that in these cases of minimal changes, genetic completion (of the conditionally complete work) can be achieved by someone else. If so, an effective completion decision does not seem to be necessary for a work to be finished, at least in the case of the artist's death. But then we are left wondering what precisely the conditions are under which a work can be posthumously completed.

Hick's ontological claims regarding posthumous works seem equally problematic. Even in cases where only minor changes are made, the posthumously published work is distinct from the work left behind by the author. Without the original artist's consent to publish, we put power in the hands of others and this, according to Hick, is unwarranted: Again, to allow such a case would be to place unwarranted power in the hands of the record executives and other individuals, a power that seems to rest firmly in the hands of the artist. ${ }^{12}$

But aren't there cases in which works can be legitimately finished (or published) after the death of their author, even without having made a completion decision? Editors and literary executors often aim to complete the work of their dead clients. But according to Hick, their efforts always result in a new and distinct work. Death clearly puts a stop to the original artist's creative process, but why is it that the creative process cannot legitimately be taken up by someone else? Why does death make a difference to whether there are two works or just one?

Consider, for instance, an artist who works all day on a painting and decides at the end of the day to cease work on it. She has made no decision regarding the genetic completion of the work nor has she made any decisions regarding whether the work is currently suitable for public consumption. She isn't sure whether the work needs to be altered and so she puts it away in a drawer and decides to return to it the next day. ${ }^{13}$ Intuitively, the work remains unfinished and it seems natural to say that when she returns to the work the next day any changes that she makes will be to the very same work she placed in the drawer the previous day. Indeed, Hick is explicit about this:

But, I suspect we are inclined to hold that, until a work is finished, any alterations made to it will not result in a work distinguishable in identity from the final work. That is to say, the process of art making leads to a finished work, and the many stages leading to this state do not identify different works, but different stages in the development of the same work. ${ }^{14}$ 
Now imagine the artist dies unexpectedly in the middle of the night. A week later her daughter finds the work, takes it out of the drawer and begins to modify it. According to Hick, the work started by the original artist and completed by her daughter is a new and distinct work from the one she left behind. But, why should the mere fact that the process is continued by the daughter, rather than the original artist, result in there being a new work? This seems too quick. Whether there is a new work here or not depends on more than merely whether the creative process is continued by the daughter rather than the original artist. Just because two people have contributed to the work, after all, does not thereby mean that there must be two works. Surely even in cases where the creative process is carried out by multiple people sequentially over time, (as in, for example, cadaver exquis works), the result is a single work, rather than multiple works. A work might be taken up by another artist and the creative process continued without a new and distinct work being created as a result.

Perhaps the intuition behind Hick's claim that when the daughter takes up her mother's work, she is thereby creating a distinct, second work is this: if the daughter produces something other than what the mother would have made, then the daughter has made a distinct work. But, by the very same reasoning, had the mother remained alive and proceeded to change ninety-nine percent of the painting the very next day, then it would seem as if the mother would have made a distinct work too. These cases highlight that distinctness is not a function of the fact that the artistic process is being continued by someone else.

Even if we grant that one can continue the creative process of another without thereby creating a new work, Hick's and Livingston's theories of completion prohibit the second artist from ever finishing the work of another. The daughter might add to the very same work her mother left behind but because their theories give the original artist the power and control to determine when a work is complete, these theories also unfortunately preclude a work from ever being completed after the original artist's death.

This suggests a radical revision of our ordinary practices, including our ordinary ways of talking about finishing the work of the dead. Editors, literary executors, family members and so on, regularly aim to bring to fruition the work of the dead. Now it could be that such ordinary practices and ways of talking are wrong. These editors and executors think they have finished the work of the dead, but they haven't. But we need independent reasons for thinking that this is the case. The mere fact that Livingston's and Hick's theories lead to a revision of our ordinary practices is not itself enough evidence to suggest that our ordinary practices are wrong. Indeed, the opposite is just as likely. The fact that Hick's and Livingston's theories conflict with our ordinary practices could very well be evidence that their theories are wrong.

But it isn't just the conflict with ordinary practice that causes problems for Hick's and Livingston's view of completion. If posthumously completed works are an oxymoron, then we will have troubling distinguishing between someone who is genuinely trying to 'finish' or 'complete' a deceased author's work - say, Christopher Tolkien's Silmarillion - from a postmodern appropriation artist who is merely mocking or quoting the unfinished fragment, or from a plagiarist stealing from Tolkien's undiscovered unfinished fragments. Intuitively, Christopher Tolkien's work bears a relationship that is unique and special to the original unfinished work (and fundamentally different from the appropriationist's or plagiarist's relationship to the original unfinished work) - 
Christopher Tolkien is actually finishing a work that was begun before the author's death. Unfortunately, Livingston and Hick seem to have no way of capturing that special relationship. In the next section, we shall provide an account of posthumous completion that can.

Both Hick and Livingston postulate conditions for a work to be finished which put power in the hands of the artist. We've identified a number of ways in which posthumous works challenge these conditions. At the very least, the case of posthumous works calls us to reconsider the ways in which control over one's own work can be exerted from the grave.

\section{Posthumous Completion and Secondary Agency}

Completing the work of another author - dead or alive - is an instance of the more general case of acting on behalf of someone else. We often ask other people to do things for us, and when they act on our behalf, the action is still attributed to us even when we have not completed the action ourselves. Consider the lawyer who writes a will for you, the representative who casts her constituencies' vote, a real estate agent who negotiates the sale of your house, parents who fill out their children's passport forms. In these cases, an agent, $\mathrm{A}$, is acting on behalf of another agent, $\mathrm{B}$, and an action is attributed to $\mathrm{B}$ on the basis of A's actions. The will is your will not your lawyer's; you buy the house, not your agent; the constituents have voted; your child has applied for the passport; and so on. To act on behalf of another is to act as a secondary agent. But not just anyone can act as a secondary agent. Secondary agents have been authorized to act on behalf of others. ${ }^{15}$ David Copp, following Hobbes, defines a secondary action as one where:

a natural person may have an action attributed to it on the basis of an action of another agent if and only if that agent acts by authority of that person. ${ }^{16}$

And where,

to act by authority of an author is to act with the power of "presenting the person of the author.' 17

Secondary agency is quite prevalent and allows one's wishes to be fulfilled after one's death. The executor of a will acts as a secondary agent and carries out the wishes of the dead. In distributing property or money left behind, the executor acts on behalf of the deceased and we rightly attribute beneficence to the dead, based on the actions that are carried out by the executor. The executor of a will is authorized by way of formal legal rules.

But secondary agents can come about by less formal means of authorization. A family friend, for instance, might become verbally authorized by the wife of the deceased to continue the charitable organization her husband established. A fellow philosopher might be authorized to present and even respond to comments at a society meeting on behalf of a speaker too sick to attend in virtue of sharing the same philosophical views. A faculty member might become authorized to speak on behalf of the department to the Dean, in virtue of the fact that he is well respected by his peers and is deemed most capable of representing their collective interests. And, secondary agency might be acquired by still other means - sometimes authorization comes about as a result of a special relation that a secondary agent has to the primary agent. So, a spouse might have 
a standing authorization to accept party invitations on your own behalf while you are at work or in a meeting, even if they have never explicitly discussed this authority (perhaps other features of your marriage make this kind of authorization implicit). A supervisor might be authorized to make certain decisions about a student's thesis, even if the supervisor hasn't explicitly discussed this with the student.

Secondary agency appears to be widespread in art-making generally: ghostwriters write on behalf of other people and these other people, not the ghostwriters, are credited with authorship; speechwriters write on behalf of politicians, actors, sportspeople, and so on; Sol LeWitt's Wall Drawings are painted by others, acting on his authority; Christo and Jeanne-Claude's environmental artworks are realized by crew persons acting on their authority; the works of Donald Judd, executed by others; works by Warhol, made in the Factory; works by Rembrandt, by those in his studio; works by Thomas Kinkade, with finishing touches done by authorized painters. ${ }^{18}$ Because these contributors are acting on behalf of the artist, the artist alone is credited as author, even though the artist did not necessarily realize the entire work.

Posthumously completed works are merely a special case of secondary agency. Whether the work that is altered or published after the artist's death is the same work as the one that the artist left behind and whether the posthumously altered or published work is actually a complete work depends on whether it is a legitimate case of secondary agency. On our view, if the posthumously altered or published work is completed by someone who has been authorized to act as a secondary agent on behalf of the deceased, then the secondary agent is effectively completing the work of the dead (and not creating a new work, as Hick's and Livingston's views imply). We shall argue that completers engaging in secondary agency do so with the intention of fulfilling the interests of the creator as best they can, and of completing the work as the creator would have wanted it. Even when completers contribute significant ideas, important features, and new ways of presenting the creator's work, the completers are doing so only on the creator's behalf, and because of this, are completing an already existing work, rather than creating a new one.

Let's consider a specific, and somewhat controversial, case of posthumous work. At the time of Kafka's death, he left many unfinished works (unfinished by either Hick's or Livingston's standards). The Trial was missing the last chapter and The Castle ended mid-sentence. Max Brod, the literary executor, edited both works, added final chapters, finished sentences, and otherwise altered the texts in various ways before publishing them as the works of Kafka. We do not have any evidence that Kafka explicitly consented to their publication (on the contrary, we have evidence that he wanted all of his work burned after his death), nor does it appear that Kafka made a completion decision of the sort that Livingston describes (again, on the contrary, he wrote to Brod expressing doubts that he would ever finish The Trial). Did Brod finish the work of Kafka or did Brod actually create new works? And if Brod substantively altered the works, are we correct in attributing the resulting work to Kafka?

There is no doubt that Brod was attempting to finish Kafka's work. His intention wasn't to create a new work somehow cobbled together from bits of Kafka's unfinished work. ${ }^{19}$ That is, Brod wanted to continue the process started by Kafka and finish the work that existed prior to Kafka's death. As his literary executor, Brod was authorized to do so. But authorized by whom? Kafka explicitly said he wanted his work to be burned 
after death. Isn't this a case in which the executor failed to carry out the wishes of the deceased and so did not act on behalf of the artist? Brod's own response to charges of unethical behavior suggests otherwise. According to Brod, Brod told Kafka he would never burn Kafka's work and knowing this, Kafka retained him as literary executor anyways. Brod had legal authority to act on behalf of Kafka and Kafka's willingness to keep Brod as a literary executor even when he knew that Brod would not burn his work reveals implicit consent.

Notice that if The Trial and The Castle are not the same works as those left behind by Kafka, as Livingston's and Hick's views imply, it is difficult for them to explain why they are still attributed to Kafka. Perhaps, following Hick, one might want to say that the work was somehow a collaboration:

We would, I suspect, have to consider such works as being collaborative works with two or more artists; however, such works would not be the same works as those that the artists left unfinished at their deaths. ${ }^{20}$

But this clearly isn't what Brod was up to. Brod wasn't collaborating with Kafka. ${ }^{21} \mathrm{He}$ was helping Kafka bring to fruition work Kafka began before his death. Perhaps instead Livingston or Hick want to say that these works ought not to be attributed to Kafka because they contain material that is not sufficiently Kafkaesque, in the stylistic sense that the posthumously finished and published work has lost the features that characterize Kafka's works. Indeed, it may be that Brod's contributions were so significant that the final work bears no stylistic resemblance to the work that Kafka left behind. We leave that to Kafka scholars to decide. But whether the work completed by Brod is Kafka's is a fundamentally different question from whether the work completed by Brod is Kafkaesque. Whether Brod finished the work poorly is a different question from whether he finished it tout court. The mere fact that Brod was authorized on Kafka's behalf to complete his works means that these posthumously completed works are still Kafka's, even if Kafka scholars agree that Brod did a lousy job of it. ${ }^{22}$ Whether the work left behind by Kafka is the same as the work that bears his name in the bookstore today depends on whether Brod was authorized to do so and whether Brod is in fact acting on behalf of Kafka.

The issue of what a completer must do in order to act on behalf of an artist is complex and varies depending on the context and the work. But it is clear that not just anyone can act on behalf of another and not just any action will be sufficient to count as acting on behalf of another. For instance, if Van Gogh left behind an unfinished painting, not just anyone can finish this painting. The conditions for secondary agency here are set either by Van Gogh himself, by his estate, or there could be some general agreement among members of the art world that only certain people are authorized to complete works by Van Gogh, if at all. The authorization process will differ depending on the artist, the genre, the culture and context of completion. Sometimes it will be laid out formally in legal documents, and other times loosely and informally.

In addition to the constraint of authorization, the authorized completer must complete the work in a certain way in order to be said to be acting on behalf of the agent. Not just any way of finishing the painting will count as acting on Van Gogh's behalf. To act on behalf of another is to act in his or her interests. 
But how, we might wonder, can one act in the interest of the dead? The dead are just that - dead. They do not exist. Thus, they have no interests.

An appeal to the literature on posthumous harm is insightful. In "Harm and Selfinterest," Joel Feinberg appeals to W. D. Ross's distinction between "want fulfillment" and "want satisfaction." 23 The fulfillment of a want, Feinberg writes, "is simply the coming into existence of that which is desired. The satisfaction of a want is the pleasant experience of contentment and gratification that normally occurs in the mind of the desirer when he believes that his desire has been fulfilled." ${ }^{24}$ The distinction between the two concepts can readily be seen when we consider that wants can be fulfilled without satisfaction (as when the achievement of a desired goal proves, in its consummation, to be joyless), or that one can feel satisfaction without fulfillment (as when one is deceived into believing, falsely, that his goal has been achieved). Feinberg contends that "harm to an interest is better defined in terms of the objective blocking of goals and thwarting of desires than in subjective terms; and the enhancement of benefiting of an interest is likewise best defined in terms of the objective fulfillment of well-considered wants than in terms of subjective states of pleasure." 25 Thus, we can fulfill the desires and interests of the dead, but not satisfy them.

In the case of posthumously completed works, the completer acts on behalf of the creator and attempts to fulfill the desires or interests of the dead creator. Just as some people help artists realize their artworks while the artist is still living, so too, can other people can help deceased artists realize their artworks posthumously by careful attention to the fulfillment of the deceased's wishes or desires. These wishes and desires may be difficult to discern but it is by no means impossible. Evidence of such wishes and desires is often found in manuscripts, diaries, correspondence, and can be extrapolated from the unfinished work itself. To the extent that all these different processes can specify the conditions under which and the person to whom the deceased author will relinquish control, it makes sense to think that the deceased author's will, estates and writings can often provide the authorization required for secondary agency. Secondary agency, in turn, explains why in many cases, a work remains authored by the original, now-deceased creator, even though many other people may have contributed to the work. Completers engaging in secondary agency do so with the intention of fulfilling the interests of the creator as best they can, and of completing the work as the creator would have wanted it. Even when completers contribute significant ideas, important features, and new ways of presenting the creator's work, because the completers are doing so only on the creator's behalf and with the intention fulfilling the interests of the creator as best they can, the deceased author remains author.

We should note here that Livingston's theory of completion might be able to handle a limited set of posthumously completed works, if he were to accept the phenomenon of secondary agency. Consider again, Livingston's completion decision:

Perhaps it would be good enough to say that in all cases where the artist agrees in advance to some "stopping rule" or decision procedure that will not have to depend upon his or her own subsequent decision about the work's completion, that other procedure is what is necessary to work completion. We can call this disjunction of two types of cases the artist's "extended completion decision," and although universal claims about this messy terrain are risky, this sort of decision may be provisionally advanced as a necessary condition on all work completion. ${ }^{26}$ 
One way to view secondary agency in the context of posthumous works is to see the primary agent as relinquishing control to a stopping rule or a decision procedure. Or rather, the artist agrees (perhaps implicitly) that the work could be finished after her death - perhaps the artist learns ahead of time that she is deathly ill, and starts planning what she wants done with the remaining works. In these cases the content of the effective completion might be something like this: " $\mathrm{X}$ is responsible for my work after my death and shall determine what is to be done with it, whether and how it is finished, and who shall finish it." Indeed, many artists leave behind explicit directions regarding their work in their wills and there might be all sorts of ways in which such an effective completion decision might be made implicitly. Kafka's sanctioning of Brod as his literary executor might have been such a case. If the content of an effective completion decision can incorporate decisions regarding who can finish the work after the artist dies (that is, who is authorized), rather than simply decisions about the content of the work, then Livingston's theory could accommodate cases of posthumous authorship in the particular situation where authors engage in the kind of extended decision rule that draws on our proposed notion of secondary agency. If the creator of a work has the power to complete a work while alive, then the process of authorizing a secondary agent essentially transfers this "power" to the hands of the completer.

Of course, this means that Livingston's account can handle a small set of posthumously completed works - viz, those where the primary agent makes an effective completion decision regarding secondary agency. But, his account will remain unable to handle cases where the primary agent dies unexpectedly or has not made any kind of effective completion decision regarding secondary agency.

Our theory of secondary agency has a further advantage to the current accounts on offer. Recall that one of the difficulties raised earlier for Hick's and Livingston's theories of completion was that it is difficult to distinguish between artists who aim to complete or finish the work of another and those who merely appropriate, quote or plagiarize the unfinished work of another. Appealing to secondary agency provides an elegant way of making such a distinction. A secondary agent is one who is authorized to act on behalf of another. Without authorization, there is no secondary agency. In cases of appropriation or plagiarism, authorization to finish the work is missing and so we do not have a case of posthumous completion of work.

It would be convenient if there were a simple set of conditions under which one is authorized to finish the work of the dead. But it is unlikely that we can find any universal conditions. The authorization conditions and processes involved in authorization will vary from different artistic and social domains. Compare, for instance, the conditions under which someone is authorized to (1) publish Michael Jackson's documentary-film This Is It, which appears to have been released simply due to popular demand, (2) complete Robert Jordan's series The Wheel of Time (chosen by his wife), (3) complete the works of Kafka (the executor), (4) complete musical works like Beethoven's Symphony Number 10 (Barry Cooper), various works by Mussorgsky (completed by a variety of different people), (5) complete the works of General Idea, after AA Bronson's death (the remaining two members of the group). Given the myriad of ways in which secondary agents become authorized to complete these works, it is highly unlikely to expect a general account of the conditions under which an agent can be come authorized 
to act on behalf of a deceased artist. But in the majority of cases, the particular context and details of a given case is usually sufficient to explain why and how (and if) a given agent has been authorized to act on behalf of a deceased author.

\section{Conclusion}

Many works of art are finished posthumously. They are finished by others and yet we attribute the work to the original artist. We have argued that if Hick's and Livingston's theories of completion are correct, there are no posthumous works and finishing the work of the dead is impossible. This is not only counterintuitive, it makes it difficult to distinguish between those who are trying to finish the work of the dead and those who are stealing or appropriating the work of the dead. In addition, we've argued that Hick's claim that an ontologically distinct work is created by those who alter the unfinished work of the dead is problematic. Continuing the artistic process of the dead is not sufficient for creating a new and distinct work. Whether one creates a new and distinct work or whether one finishes the same work left behind by the dead depends on whether the completer is authorized to act on behalf of the deceased artist.

We have introduced the notion of secondary agency (being authorized to act on behalf of another) in order to make sense of how one can finish the work of the dead and still credit the deceased with authorship. We have also suggested that Livingston could supplement his theory of completion with the notion of secondary agency in order to accommodate a limited set of cases of posthumous authorship, viz., those where authors make an effective completion decision regarding secondary agency. Our focus has been on posthumous works but secondary agency is widespread in the art world.

Art scholarship and aesthetic understanding would be significantly expanded with further research into the different ways that secondary agency can be authorized in different artistic domains. Art scholars themselves are in a privileged position to explore further the ways in which various interactions among artists can sanction some artists, but not others, to act as a secondary agent. Likewise, the study of certain kinds of artforms, like appropriation art and participatory art serve to challenge the authority of the artist, and to explore the different dynamics between different people engaged in different ways, in different capacities and in different roles in the art-making process. Philosophers of art would have much to learn from art scholars providing more in-depth analyses of these artistic relations among artists and its impact on the nature of art. And, conversely, art scholars would have much to learn from philosophers providing more nuanced and refined accounts of agency in art-making.

We hope our discussion here might spark further discussion regarding the role of secondary agency in the art world and the concepts of agency, control, and authorization.

${ }^{1}$ Livingston, "Counting Fragments and Frenhofer's Paradox", British Journal of Aesthetics, 39(1), 14-23. Art and Intention: A Philosophical Study, Oxford University Press, 2005. He draws on these notions in his more recent works, Cinema, Philosophy, Bergman: On Film as Philosophy, Oxford University Press, 2009, chapter 2, and in 
"Artistic Collaboration and the Completion of Works of Art", co-authored with Carol Archer, in British Journal of Aesthetics, 50(4), October 2010, 439-455.

${ }^{2}$ Livingston, Art and Intention, 55.

${ }^{3}$ Livingston, Art and Intention, 56.

${ }^{4}$ Livingston, "When a Work is Finished: A Response to Darren Hudson Hick", Journal of Aesthetics and Art Criticism, 2008, 66: 393-5.

${ }^{5}$ Livingston, "When a Work is Finished: A Response to Darren Hudson Hick", 394.

${ }^{6}$ Livingston, "When a Work is Finished: A Response to Darren Hudson Hick", 394.

${ }^{7}$ Livingston and Archer, "Artistic Collaboration and the Completion of Works of Art", 446.

${ }^{8}$ Livingston, "Counting Fragments and Frenhofer's Paradox", 17.

${ }^{9}$ Livingston, "Counting Fragments and Frenhofer's Paradox", 18.

${ }^{10}$ Hick, "A Reply to Paisley Livingston", Journal of Aesthetics and Art Criticism (2008): 66(4): 397.

${ }^{11}$ Hick's emphasis, "When Is a Work of Art Finished?", Journal of Aesthetics and Art Criticism, 66(1): 74-5.

${ }^{12}$ Hick, "When Is a Work Finished?" 72.

13 This is essentially the case that Hick considers in his "When Is a Work of Art Finished?", 69-70

${ }^{14}$ Hick, "When Is a Work of Art Finished?", 72.

${ }^{15}$ See David Copp ("Hobbes on Artificial Persons") for a more thorough discussion of secondary agency. "Hobbes on Artificial Persons and Collective Actions" The

Philosophical Review, 89(4), October 1980, 579-606.

${ }^{16}$ Copp, "Hobbes on Artificial Persons" 600.

${ }^{17}$ Copp, "Hobbes on Artificial Persons" 593.

${ }^{18}$ Of course, in some of these cases of secondary agency, the primary agent still gets 'final say', the right to change or refuse what the secondary agent has produced on behalf of the primary agent. And, intuitively this is a big difference with the posthumous case, where the deceased author doesn't get any final say. However, many artists relinquish this option - Sol LeWitt and Thomas Kinkade, for example - and these cases are quite similar to the posthumous case.

${ }^{19}$ And even when literary executors, like Paine, did in fact cobble together different bits of work by Mark Twain, he did not do so with the intention to create a new work by Paine - rather, he did so with the goal of continuing the process started by Twain and finishing the work that existed prior to Twain's death.

${ }^{20}$ Hick, "When Is a Work of Art Finished?", 76, footnote 28.

${ }^{21}$ And, indeed, it is impossible to collaborate with the dead, as Hick suggests in his footnote. For, if, as most theories of joint action suggest, collaboration requires something like shared intentions, joint commitments, or we-intentions, and if the deceased can't have such beliefs, intentions or commitments, then collaboration with the dead is impossible. There is no such thing as a one-way collaboration, which is the situation for posthumously completed works.

${ }^{22}$ It may be difficult to tell whether Brod was just doing a poor job of completing the work on behalf of Kafka, or whether Brod was not interested in acting on Kafka's behalf, and was simply completing the work to further Brod's own interests. It may be that in 
this case it is difficult to tell whether the completer intended to act on behalf of the deceased author, or whether they were intending to complete it on the completer's own behalf. Discerning intentions is always difficult - but not impossible. Relying on patterns of self-serving behavior, knowing about the interests of different parties and the rules and context of a particular situation, we make these judgments all the time in the ordinary world - when we decide whether parents are really acting on behalf of their children, whether a CEO is acting on behalf of a company, whether a head of department is acting on behalf of the program, and so on. We discuss this in more detail on p. 19.

23 "Harm and Self-Interest," in Law, Morality and Society: Essays in Honour of H. L. A. Hart, ed. P. M. S. Hacker and J. Raz (Oxford: Clarendon Press, 1977), 284-308

${ }^{24}$ Feinberg, "Harm and Self-Interest," 302.

${ }^{25}$ Feinberg, "Harm and Self-Interest," 303.

${ }^{26}$ Livingston, "When a Work is Finished: A Response to Darren Hudson Hick”, 394. 